\title{
SPREAD OF INFLUENZA IN A FACTORY
}

\author{
BY
}

\section{FIONA ACHESON and DAVID HEWITT \\ From the Institute of Social Medicine, Oxford}

It is generally agreed that colds, influenza, and other respiratory ailments are among the principal causes of sickness absence in industry, and that some of this absence results from cross-infection between fellow-workers. The total working days lost far exceeds those lost for other reasons, such as industrial disputes, yet comparatively little study has been devoted to the subject of infection in factories. Experiments with ventilation equipment, ultra-violet irradiation, etc., are considered too costly, too time-consuming, or too difficult to assess. Thus the factors which favour or restrict infection at work are not precisely known. In theory, it should be possible to learn a great deal from statistics of sickness absence. In practice, sickness absence rates are so profoundly influenced by the age and sex of the workers and the season of the year that valid comparisons between departments or factories require more elaborate standardization than existing records allow. An even more serious defect is that the records rarely include sufficient data about such conditions of work as are likely to affect morbidity.

The difficulty of standardization can be by-passed in a study restricted to rates of absence from influenza, since this disease does not discriminate between men and women, affects all age-groups, and tends to occur in relatively short and well-defined epidemics. If the records also include a nucleus of environmental data, some of the laws governing cross-infection at work may be elucidated.

This paper describes the use made of an opportunity provided by the 1951 influenza epidemic. The material collected was too slight to support any original methods of analysis, but it did provide an interesting sequel to a previous study of the spread of tuberculosis in factories (Hewitt and Stewart, 1951).

\section{MATERIAL}

On January 12 it was reported that a considerable number of cases of influenza were occurring amongst the employees of the University Press, Oxford. One of us (F.A.) then began a series of visits to the factory in the course of which she interviewed every employee who was absent from work for any cause at any time between December 1 and February 15. For all persons who were absent the following information was obtained: first day of absence; day of return to work; reason for absence.*

Those who were diagnosed as cases of influenza were also asked whether they had had home contact with the disease before falling ill, whether they had obtained a doctor's certificate, and when exactly they had sickened. Much additional information was also collected by observation and from factory records, including the number of persons working in each room, the floor measurements of each room with a plan of the layout, and the ages of all employees.

* The mere statement by a worker that he did or did not have influenza was not accepted without satisfactory confirmation from answers to other questions. The points regarded as essential to the diagnosis were coryza, pyrexia, "aches and pains", depression, and lassitude. 
When the offices as well as the workshops were included, there was found to be a total of 51 occupied rooms, containing 752 workers. During the span of the epidemic (December 27 to February 2), there were 145 cases of influenza with no recurrences, an overall incidence of $19 \cdot 3$ per cent. During the same period, 141 persons recorded one or more absence from causes other than influenza. The distribution of these absences by cause and by sex is shown in Table I.*

TABLE I

Distribution of All Absences by Cause and by Sex of Workers

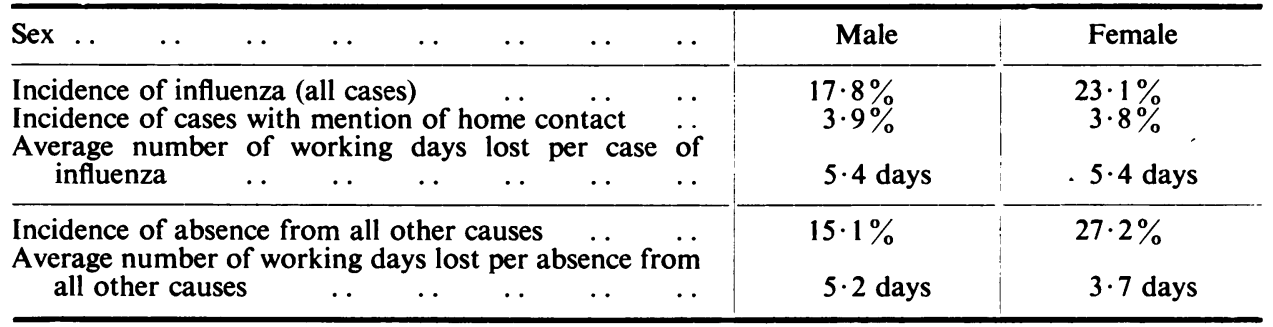

Judging by the average number of working days lost, the disease appears to have taken a milder form than in the contemporary epidemic at Widnes and Runcorn reported by Potter (1951), where the average duration of absence was stated to be 14 to 21 days.

The average number of days lost in Oxford was exactly the same for men as for women, and the rather greater case incidence amongst women is not statistically significant.

In only one-fifth of the cases did questioning elicit any mention of a home contact with influenza before the development of symptoms.

A more detailed analysis of the absences due to influenza is given in Table II.

TABLE II

Distribution of Influenza Absences by Age and Sex

\begin{tabular}{|c|c|c|c|c|c|c|}
\hline & Sex & & Age Group & $\begin{array}{l}\text { Cases of } \\
\text { Influenza }\end{array}$ & $\begin{array}{l}\text { Estimated } \\
\text { Population } \\
\text { at Risk }\end{array}$ & $\begin{array}{l}\text { Estimated } \\
\text { Incidence of } \\
\text { Influenza } \\
\text { (per cent.) }\end{array}$ \\
\hline Male & & . & $\begin{array}{l}\text { Under } 25 \\
25-44 \\
45 \text { and over }\end{array}$ & $\begin{array}{l}27 \\
26 \\
43\end{array}$ & $\begin{array}{l}120 \\
193 \\
227\end{array}$ & $\begin{array}{l}22 \cdot 3 \\
13 \cdot 5 \\
18 \cdot 9\end{array}$ \\
\hline Female & .. & . & $\begin{array}{l}\text { Under } 25 \\
25-44 \\
45 \text { and over }\end{array}$ & $\left.\begin{array}{r}35 \\
2\end{array}\right\} 14$ & $\left.\begin{array}{l}154 \\
46 \\
12\end{array}\right\} 58$ & $\begin{array}{l}22 \cdot 7 \\
24 \cdot 1\end{array}$ \\
\hline \multicolumn{3}{|c|}{ All Groups } & . & 145 & 752 & $19 \cdot 3$ \\
\hline
\end{tabular}

A $\chi^{2}$ test was used to compare the numbers of cases observed and the numbers of workers estimated to have escaped influenza with the numbers expected on the hypothesis that risk of infection is independent of sex and age. This gave a value of $\chi^{2}$ equal to 7.05 which, with four degrees of freedom, lies between the 20 per cent. and 10 per cent. points of $P$, i.e. the observed variations between sex and age groups are not statistically significant.

The result of applying a statistical test to Table II is to show that it does not contain evidence of any significant variation in incidence between the sexes or between the age groups

* The sex of workers was only recorded during the survey for those persons who were absent. The incidence rates of influenza and other absences in Tables I and II are therefore based on the numbers of each sex working in the factory in December, 1950. This qualification does not apply to the other incidence rates quoted in this paper, nor does it affect the average number of days lost per absence. 
considered. This is in accord with the observation of Padley (1947) . . .

Influenza shows a fairly level relative incidence throughout life . . . There is in these

figures no indication of a developing immunity against influenza . . .

Consequently no standardization of incidence rates has been considered necessary in the following arguments despite the fact that the groups of workers considered do not have identical sex and age composition. It is probable that the appearance of variation in Table II is a result rather than a cause of the statistically significant variation in Table IV.

\section{Spatial Distribution of CASES}

In addition to the written records, a plan was kept of each room in which influenza occurred, on which the working place of each victim was marked and dated. There was an appearance of "clumping" in some of the rooms which suggested an association between exposure to draughts and liability to develop influenza. But when the timing of the cases was considered it was found that the plans did not provide any evidence for a chain of infection linking successive cases or generations of cases. This was not taken to mean that no cross-infection had been taking place, for two reasons:

(i) Different powers of resistance in individual workers, together with the operation of chance factors, would make the visible distribution of cases very different from any invisible chain of infection which might exist.

(ii) It had been shown in the previous study of tuberculous infection that no contradiction arose from assuming that all workers in the same room are within infecting range of each other, and not merely those who work close together. That this may hold true for influenza as well as tuberculosis is suggested by Table III.

If proximity within a room is an important factor in determining the risk of crossinfection, then rooms where workers are closer together should, other things being equal, show a higher incidence of illness than rooms in which they are further apart. In Table III each room for which floor measurements were obtained has been allotted to one of three groups defined by the ratio of floor area to number of occupants.

Some of the minor rooms and offices with twelve occupants or less were not measured and are therefore omitted from Table III. Altogether in these omitted rooms there were 118 workers with thirteen cases of influenza. Maintenance workers (37 workers with ten cases of influenza) are also excluded from Table III since their duties involved periods of work in several different rooms.

TABLE III

INCIDENCE OF INFLUENZA RELATED TO SPACING OF WORKERS

\begin{tabular}{c|c|c|c|c}
\hline $\begin{array}{c}\text { Range of } \\
\begin{array}{c}\text { Area-per-worker } \\
\text { (sq. ft) }\end{array}\end{array}$ & $\begin{array}{c}\text { No. of Workers } \\
\text { in such Rooms }\end{array}$ & $\begin{array}{c}\text { Cases of } \\
\text { Influenza }\end{array}$ & $\begin{array}{c}\text { Incidence } \\
\text { per cent. }\end{array}$ & $\begin{array}{c}\text { Average Area- } \\
\text { per-worker } \\
\text { (sq. ft) }\end{array}$ \\
\hline $\begin{array}{c}\text { 0 to } 99 \\
100 \text { to } 199\end{array}$ & 207 & 50 & $24 \cdot 2$ & 76 \\
200 or more & 216 & 39 & $18 \cdot 1$ & 128 \\
\hline All Measured Rooms & 174 & 34 & $20 \cdot 6$ & 160 \\
\hline
\end{tabular}

To test the hypothesis that the incidence of influenza was not affected by the amount of area-perworker, a $3 \times 2$ contingency table was formed of the numbers of workers in each group who did and who did not fall ill. This gave an insignificant value of $\chi^{2}(2 \cdot 58$ for two degrees of freedom, $P>\cdot 20)$. 
The differences in incidence which appear to be associated with differences in area per worker are well within the range of chance variation, and there is no evidence that the risk of infection was associated with the distance between workers. It might be argued that area per worker is an inadequate index of the proximity of workers. But it was found that attempts to measure mean linear distance between workers, or to substitute airspace for floor-space, begged many questions and settled none. Since neither the room plans, nor the analysis in Table III revealed any tendency for infection to pass more easily between the closest neighbours than between more widely separated workers, it has been assumed that at any given moment risk of infection is the same in all parts of a room.

\section{Relation OF Infection Risk to Number of CONTACTS}

Each room in the factory was placed in one of three groups according to the number of workers it contained, and the influenza experience of the three groups is arranged for comparison in Table IV. The maintenance workers are again excluded because they cannot be allotted to any particular room or group of rooms.

TABLE IV

INCIDENCE OF INFLUENZA RELATED TO NUMBER OF WORKERS PER ROOM

\begin{tabular}{c|c|c|c}
\hline Workers per Room & $\begin{array}{c}\text { Number of Workers } \\
\text { in such Rooms }\end{array}$ & Cases of Influenza & Incidence per cent. \\
\hline $1-15$ & 197 & 23 & $11 \cdot 7$ \\
$16-75$ & 308 & 65 & $21 \cdot 1$ \\
76 or more & 210 & 47 & $18 \cdot 9$ \\
\hline Total & 715 & 135 & $18 \cdot 9$ \\
\hline
\end{tabular}

When the number of workers in each of the three room-groups who did or did not fall ill, was arranged in a $3 \times 2$ contingency table, a value of $\chi^{2}=7 \cdot 58$ was obtained for two degrees of freedom. The corresponding value of $\boldsymbol{P}$ is between 2 and 3 per cent. which denotes significant association between number of workers per room and the incidence of influenza.

The result of applying a statistical test to Table IV is to show that the risk of influenza was definitely lower in the small rooms of the factory than in the larger rooms. Sex and age differences - themselves not of significant magnitude-cannot be responsible for this result, since the small rooms in the factory contain a relatively large proportion of women who, in the factory as a whole, had a slightly higher incidence than men. The proportion of men belonging to the age group with the lowest incidence was no greater in these rooms than in the factory as a whole. It may be alleged that a higher employment status or "sense of responsibility" could reduce the number of cases of sickness absence in office workers. To this there are two answers. In the first place, when the factory is divided by size of room, as in Table IV, many of the junior clerical staff are found in the smallest rooms, while the largest rooms contain most of the highly-skilled and best-paid workers. In the second place, the illnesses diagnosed as influenza in this study reduced sufferers to a condition in which the effort of brainwork became intolerable. A piece of evidence which reinforces our interpretation of Table IV is provided by the proportion of cases in which a home 
contact with influenza was reported: 8 out of 23 in the small rooms, 21 out of 112 in the remainder of the factory. This means that 35 per cent. of the cases in the small rooms compared with only 18 per cent. in the large rooms had a known previous contact with the disease at home.

In short, low incidence seems to have been characteristic of the small rooms as such, not the result of any incidental circumstance. This justifies the belief that in each room the risk of influenza was related to the number of potential sources of infection in the room. It is interesting to note that the observed difference in incidence occurs chiefly in passing from the first to the second group of rooms in Table IV, while the increase between the second and third is negligible. This "early saturation" feature accords with what was to be expected (on the basis of the theory advanced in the earlier paper) of a disease spread by a relatively large number of infectious persons. This point is developed in the discussion below.

\section{Distribution of CASes in Time}

Table $\mathrm{V}$ shows the distribution of cases according to the day of the week on which sickening occurred. The shape of the epidemic curve was such that, if there had been no weekly pattern of infection, each day total (composed of six individual days cases) would have the same expected value of 20.9.

TABLE V

Frequency of Influenza Cases According to Day of Sickening

\begin{tabular}{c|c|c|c|c|c|c|c}
\hline Sunday & Monday & Tuesday & Wednesday & Thursday & Friday & Saturday & Total \\
\hline 19 & 22 & 20 & 19 & 19 & 33 & 13 & 145 \\
\hline
\end{tabular}

If, however, the aggregation of workers in a factory constitutes a special infection risk, then on Monday, when workers return to the factory from the relative seclusion of the week-end, more persons should be infected than on any other day. Provided also that there is some well-defined incubation period, one day of the week should have a particularly heavy case incidence. In fact, the figure for Friday in Table V is suggestively high - and the figure for Saturday suspiciously low.

A $\chi^{2}$ test of the departure from equal daily frequencies gives a value of $\chi^{2}=10 \cdot 7$ with 6 degrees of freedom, which falls just beyond the 10 per cent. level of significance.

Although no weekly cycle of infection can be proved from Table $V$, the apparently well-defined maximum occurring on Fridays would be consistent with such a cycle, and with a modal incubation period of four days. It is of interest to compare this result with the report of Hope Simpson (Bradley, 1951) who found no modal interval between first and second cases of influenza in the same family.

\section{Discussion}

It seems clear that influenza, like tuberculosis, is a greater hazard to the factory worker when he is employed in a large room than when he is employed in a small one. But it does not follow that the relation between risk of infection and numbers of 
workers can be formulated in the same way for these two very different diseases. In fact, the task of assessing the risk of influenza presents a more difficult problem.

First we may restate the theory of the previous paper on tuberculosis. We employ the following notation:

$(U+1)=$ the number of people in a special group which is sufficiently compact for a specified infection to pass from any one member to any other. Examples might be the group of persons using a certain swimming bath, or the workers in a particular workshop. Each member has $U$ contacts within the group who may or may not be infectious. He also has, as a member of the general community, a further number of contacts which we call $D$. It is assumed that, in any sufficiently large group, the average value of $D$ will be the same as in the community of which that group forms a part.

$M=$ the percentage of a group of persons who will develop a disease within a specified period under conditions of maximum exposure to (i.e. certainty of) infection. This depends on the resistance of the group to disease in general as well as the degree of acquired immunity.

$\pi=$ the proportion of the members of a community who are carriers of a disease, or who are infectious at some time during the period.

$y=$ the expected percentage incidence of a disease during the period for which $M$ and $\pi$ have been defined.

Then we have

$$
y=M\left\{1-(1-\pi)^{D+U}\right\}
$$

The expected incidence, $y$, is an increasing function of $(D+U)$ with a maximum value, $M$, which it approaches at a speed determined by the "carrier rate", $\pi$.

If infectious persons are as rare as in the case of tuberculosis, there will still be important increases in $y$ as $(D+U)$ passes from 200 to 300 and beyond. But when they are as common as the sources of influenza virus during an epidemic, then $y$ will, for all practical purposes, be at its maximum before $(D+U)$ reaches 50 . This offers an explanation of the relatively minute difference between the incidence in the second and third groups of Table IV, and suggests that the highest observed incidence lies near $M$. We may therefore take 23 per cent. ${ }^{*}$ as a reasonable estimate of $M$. That is to say, just under a quarter of this factory population were susceptible to attack during the epidemic.

Some idea of the average carrier rate can also be obtained. For present purposes a "carrier" may be defined as a person who, although beginning to sicken for influenza, is nevertheless present in the factory. The number of workers whose answers to questions indicated that they had been carriers in this sense was 44 , which, divided by the total population at risk, gives an estimated value to $\pi$ of 0.057 for the factory as a whole.

* When the maintenance workers, who move from room to room through the factory, are added to the third group in Table IV we have: workers, 247; cases, 57 ; incidence, $23 \cdot 1$ per cent. 
In the tuberculosis study, values of both $\pi$ and $D$ were obtained from data concerning morbidity in rooms of different sizes by means of the estimating equation given above. This involved making two assumptions which seemed fair in the case of the tuberculosis study but are not of general validity. In the first place it had to be assumed that sources of tuberculosis infection were evenly distributed throughout all sizes of workshop in the industrial community studied. At the very beginning of an influenza epidemic, infectious persons may well be distributed at random, in which case the equation will describe the relation between risk and size of room. But if cross-infection is taking place this random distribution will only apply during the first generation of cases. During the second and successive generations of the epidemic the proportion of infectious persons will be higher in the large than in the small groups. That is, instead of being a constant, $\pi$ will itself become an increasing function of $U$, and the estimating equation cannot be used to obtain estimates of $\pi$ unless $D$ is already known.

The second assumption of the tuberculosis study concerned the duration of exposure to infection. Here the main source of infection which had to be considered was the worker in whom the disease might pass unrecognized, or be ignored for months and sometimes for years. During this time he would distribute sufficient bacilli to cause disease in any other regular occupant of his workshop who was susceptible. But the sources of influenza virus were workers sickening for an illness which would cause them to withdraw from the factory very quickly, possibly before the room as a whole had been infected. In rooms where this happened the expected incidence would be lower than $M$ by an unknown amount. Only in rooms which contained a succession of infectious cases could we be at all confident that every potential victim had fallen ill.

This discussion illustrates the need for more study of the way in which patterns of infection at work may be represented. An improved model of the factory epidemic should dispense with the two assumptions here discussed. It should also treat the epidemic as a "stochastic" process (Bailey, 1950), avoiding the determinism of the usual over-simplified treatment. On the other hand, it should be simple enough to use for estimating purposes or it will give no practical guidance on the likely results of this or that policy of control.

The only obvious way in which a factory epidemic of the kind described could be controlled is by reducing the carrier rate. If it were possible to keep sickening workers out of the factory, or to persuade them to leave as soon as they began to feel ill, some advantage could be gained. This is especially difficult in the case of a disease which reaches a highly infectious stage without warning, besides which any system of sponsored absence from work would be open to abuse. But two assertions may be made with reasonable confidence:

(i) It is not necessary to accept the pessimistic view of Potter (1951) that

It is probable that any method intended to obviate or reduce the risk of becoming infected at work will have little effect in the total incidence of the disease.

For if the risk of infection in the larger rooms of this factory had only been 
reduced to the level of the risk in the small rooms, then about half the cases of influenza would have been prevented, and this would have been a net reduction in total incidence.

(ii) Little short of the complete exclusion of infection could have prevented the generation of some new cases in rooms with very many workers. A comparatively modest programme of control would, however, be a paying proposition in factories where the rooms are all fairly small.

An attempt must be made in some future study to relate varying sickness incidences within and between factories to other environmental factors which may facilitate or hamper the passage of upper respiratory infections between workers. Among these atmospheric temperature in the workshop has a claim to early investigation.

\section{SUMMARY}

(1) An epidemic of influenza in a factory is described and analysed. It is found to reproduce two features of infection in workshops previously observed in the case of tuberculosis:

(a) Risk of infection is not related to the proximity of workers within the rooms.

(b) Risk of infection is related to the number of workers in a room.

The form of this relation suggests that, for the purpose of respiratory infection, each worker may be regarded as in effective contact with every other regular occupant of his room.

(2) Some of the difficulties of setting up a theoretical model for a factory epidemic are discussed.

Our thanks are due to the Printer to the University and to the employees of the University Press, in particular the staff of the Personnel Department, whose generous co-operation made this study possible. We also wish to acknowledge the help we have obtained from our colleagues Dr. Josefine Webb and Dr. Alice Stewart.

Bailey, N. T. J. (1950). Biometrika, 37, 193.

\section{REFERENCES}

Bradley, W. H., (1951). Proc. roy. Soc. Med., 44, 789.

Hewitt, D., and Stewart, A. (1951). British Journal of Social Medicine, 5, 209.

Potter, A. L. (1951). Brit. J. industr. Med., 8, 91. 